\title{
The Design of Tris(o-phenylenedioxy)cyclo- trisphosphazene (TPP) Derivatives and Analogs toward Multifunctional Zeolite Use
}

\author{
Godefroid Gahungu, Wenliang Li, and Jingping Zhang \\ Faculty of Chemistry, Northeast Normal University, Changchun 130024, China \\ zhangjingping66@yahoo. com. cn
}

\begin{abstract}
Taking tris(o-phenylenedioxy)cyclotrisphosphazene (TPP) as template, series of derivatives and analogs were designed with the aim to investigate the structural features of organic zeolite $(\mathrm{OZ})$ and their potential applications. On the basis of DFT-PBE0/6-31G** quantum calculation, the results show a tight dependence of the electron donor (E-D) of the entire molecule on that of the side group and bridge. It was found that extending the side fragment with a phenyl ring and substituting $\mathrm{CH} / \mathrm{N}$, or tetrathiafulvalene (TTF)-like group, or the side phenyl fragments substitution by TTF and its derivatives, preserve the "paddle wheel" molecular shape, a key factor in the tunnel formation on which is based the organic OZ use of TPP. In comparison with the commonly used organic superconductors, most of the designed molecules with TTF fragments were predicted to show comparable or better E-D strength.
\end{abstract}

Keywords: molecular design, DFT, organic zeolite, TPP, TTF.

\section{Introduction}

The absorption properties of materials are emerging as a forefront issue of present day research, due to the strategic industrial and environmental applications, such as gas storage, selective gas recognition, and separation [1]. As a result of their unique features, molecular self-assembled materials and organic zeolites (OZ) [2, 3] seem to constitute a competing alternative in this field, and are thus still to be explored extensively. Originally studied by Allcock [4], tris $(o$-phenylenedioxy)cyclotriphosphazene (TPP, 1a) became a compound of choice to investigate the structural features of OZ and their potential applications.

Studies focused on the stability of the hexagonal modification compared to compact guest-free monoclinic [5], the investigation of gas storage or aromatic guest insertion by advanced NMR techniques [6], the confinement of $I_{2}$ molecules by several crystallization procedures [7], and the insertion of dipolar molecules [8]. From TPP to some of its derivatives, it has been shown that the available space for absorbates can be modulated by the choice of the side group, which substitutes the dioxyphenylene in the former, the key-factor of the tunnel formation being reported to be the rigid "paddle wheel" molecular shape and the requirements of the crystal state [9]. For example, it was reported that TPP and tris(2,3-dioxynaphthyl)cyclotri-phosphazene, (TNP, 2a) 
spontaneously form inclusion adducts with benzene, toluene, heptane, octanes, and many other compounds $[4,10,11]$. With 1a and some of its derivatives, clathration was characterized as a pure mechanical phenomenon [12]. Some of its relevant applications however, may be based on physico-chemical properties. Within TPP zeolite, which shows a strong affinity to include gaseous $\mathrm{CH}_{4}, \mathrm{CO}_{2}[6 \mathrm{~b}], \mathrm{I}_{2}$ and $\mathrm{Xe}[6 \mathrm{a}, 7,13]$, specific host-guest interactions of the donor-acceptor type are expected for channels. Recent report by Hertzsch $\mathrm{T}$. has shown that 1a may be used to remove radioactive $\mathrm{I}_{2}$ [6b], even from a humid environment or water [14]. The stability of the inclusion compound TPP $\left(\mathrm{I}_{2}\right)_{0.75}$ up to $420 \mathrm{~K}$ [7], was interpreted based on the Lewis acidity of $\mathrm{I}_{2}$ and the electron-donor (E-D) capacity of the TPP-phenylenedioxy rings. It appears clear that the E-D capacity may play a certain role in the trapping process of some compounds within TPP OZ, which may provide some potential applications in the environmental chemistry. From this viewpoint, different TPP-like materials (Fig. 1) are studied in this contribution. We focused our interest on the relationship between the E-D capacity of the side fragment (part C), bridge (part B), and that for the entire molecule. Although a number of theoretical works on phosphazene containing systems can be found in the literature $[15,16]$, very few were devoted to related OZ and the relationship between E-D and the structure of molecules [16]. This contribution may provide some helpful insights toward the understanding of TPP-like OZ uses and the further design as well.

\section{Computational Strategy}

Taking TPP or TNP molecular structure as template, we have designed series of TPP or TNP analogs by systematically extending or substituting the side fragment with a phenyl ring and substituting $\mathrm{CH} / \mathrm{N}$, or tetrathiafulvalene (TTF)-like group, or the bridge $\mathrm{O}$ substituted by $\mathrm{NH}$ totally or partially as described in Fig. 1. All molecular geometry optimizations were carried out with the aid of Gaussian 03 package [17]. During the geometry optimization, the neutral species were constrained within the $C_{3}$ symmetry. Density functional theory (DFT) calculation using the PBE0 functional [18] with the 6-31G(d,p) [19] basis set was performed in the geometry optimization, which was proved to be proper for such kind of system [16a]. The equilibrium structures were located using analytical energy derivatives. To confirm the structure is a minimum on the potential energy surface at this level of theory, frequency calculations were performed. The unrestricted formalism was used for the oxidized forms and uniformly estimated from PBE0/6-31+G $(\mathrm{d}, \mathrm{p})$ calculation including diffuse functions needed to describe the cations. From the calculated $\left\langle S^{2}\right\rangle$ values, the spin contamination included in the present calculation results was confirmed to be in general no more than $3 \%$. IP of the molecules were calculated as described in the equation below:

$$
I P=-E_{\text {НОмо }}
$$

Where $E_{\mathrm{HOMO}}$ is the HOMO energy (according to the Koopman's theorem [20]) at the $\mathrm{HF} / 6-31 \mathrm{G}(\mathrm{d}, \mathrm{p})$ level. Our preliminary calculations have proved that based on Koopman`s theory, the HF/6-311+G* can yield an excellent accuracy for adiabatic IP [16]. 

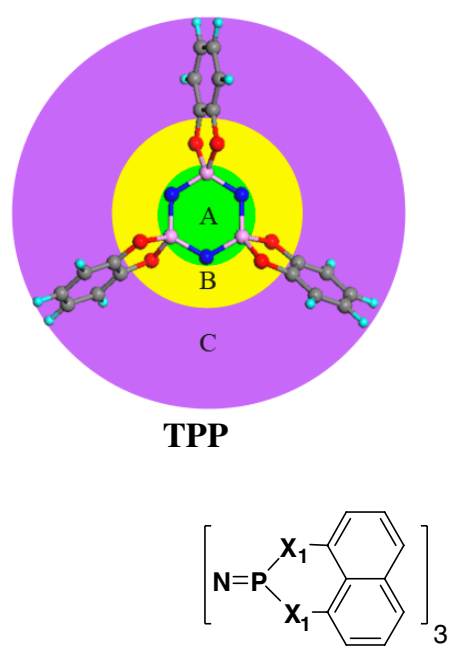

3<smiles>[Y][Y]([Y]#CC)=NC</smiles>

5

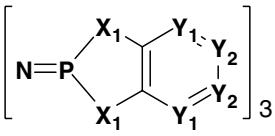

1

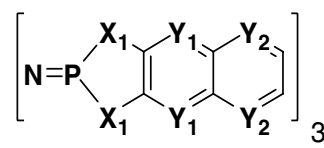

2<smiles>CC(C)=[PH]1Oc2ccc3ccccc3c2O1</smiles>

4

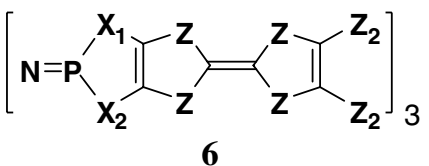

a: $\left(\mathrm{X}_{1}, \mathrm{X}_{2}\right)=(\mathrm{O}, \mathrm{O}) ; \mathbf{b}:\left(\mathrm{X}_{1}, \mathrm{X}_{2}\right)=(\mathrm{O}, \mathrm{NH}) ; \mathbf{c}:\left(\mathrm{X}_{1}, \mathrm{X}_{2}\right)=(\mathrm{NH}, \mathrm{NH})$;

1a, 2a: d: $\left(\mathrm{Y}_{1}, \mathrm{Y}_{2}\right)=(\mathrm{CH}, \mathrm{N})$; e: $\left(\mathrm{Y}_{1}, \mathrm{Y}_{2}\right)=(\mathrm{N}, \mathrm{CH})$;

5, 6: f: $Z=S ; \mathbf{g}: Z=S e ; \mathbf{h}: Z_{1}=O ; i: Z_{1}=S ; \mathbf{j}: Z_{2}=H ; \mathbf{k}: Z_{2}=C_{3}$

Fig. 1. Chemical structures of the derivatives and analogs of TPP under investigation

\section{Results and Discussion}

It is found that the geometry of the core ring is independent of the variation of bridge atom and/or side fragment. All the structures of investigated compounds preserve the "paddle wheel" molecular shape (as schematically shown in Fig. 2 as examples), a key factor in the tunnel formation on which is based the organic OZ use of TPP as soft material. In general, a good agreement was found between the calculated structures and available crystal data [5, 12a]. The frontier molecular orbital (FMO) distribution of investigated compounds all localized on their three spirocyclic side groups, as shown in Fig. 3. The E-D strength of the phenyl ring within TPP affects the stability of the adsorbent $\cdots$ adsorbate complex [7]. Therefore, we demonstrated herein a tight relation between the IP of TPP-like molecules and that of the free side fragment. Then, one may directly estimates the effect of the substitution on the bridge; the $\mathrm{CH} / \mathrm{N}$ heterosubstitution on the side fragment; the extending of side group by extra phenyl ring or TTF-like fragment; and the substitution of phenyl by TTF-like fragments for the E-D capacity of TTP and its analogs from the IP of the entire molecules. The obtained electronic properties such as the IP, FMO energies, and energy gaps 
between HOMOs and LUMOs are summarized in Table 1. Furthermore, the optimized structures for the neutral and cationic species for investigated compounds only revealed small structural changes, suggesting being the good candidates for $\mathrm{OZ}$ use.

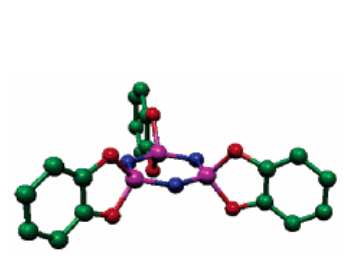

1a

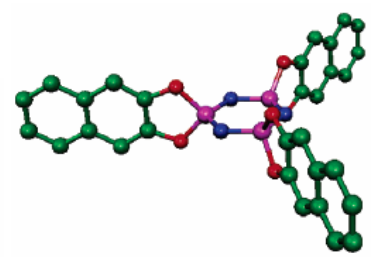

2a

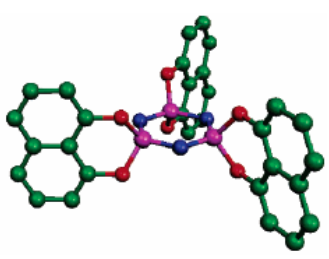

3a

Fig. 2. Optimized geometries for 1a-3a (for clarity, hydrogen atoms are not shown)
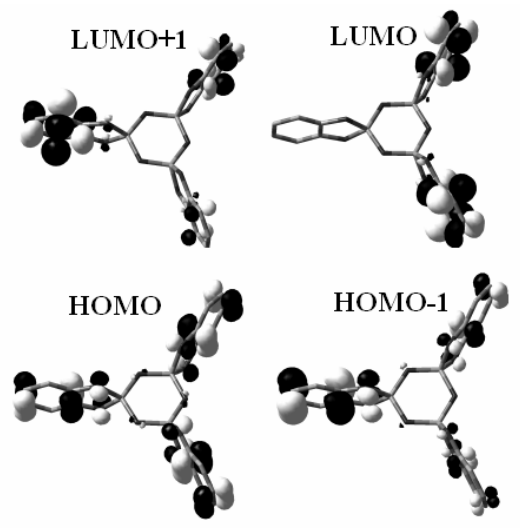

Fig. 3. Frontier Molecular Orbitals for 1 a computed at PBE0/6-31G(d,p)

\subsection{The Effect of Enhanced $\pi$ Conjugation and the Bridge O/NH Partially or Totally Substitution}

We begin our discussion with the already synthesized compounds (1a-3a) and 4a which correspond to extending the phenylenedioxyl side group (within TPP) with one more phenyl rings, linearly (2a) or laterally (3a, 4a). Some of the corresponding optimized structures are displayed in Fig. 2. In agreement with experimental observations is the planarity of the side fragment in the cases of 1a, 2a, and of course, the twisted heterocycle (containing the two $\mathrm{O}$ atoms) in $3 \mathrm{a}$. With the aim of evaluating the influence of $\mathrm{CH} / \mathrm{N}$ heterosubstitution on the molecular structure of TPP and TPP-like molecules, compounds 1a and 2a were considered for this issue.

As clearly summarized in Fig. 4, the results suggest that (i) the $\mathrm{O} / \mathrm{NH}$ substitution increases both the $E_{\mathrm{HOMO}}$ and $E_{\mathrm{LUMO}}$ energies in the sequence $N \mathrm{a}<N \mathrm{~b}<N \mathrm{c}$ (with $N=$ 1,2 , and 3 ) and (ii) $\pi$-conjugation increases the $E_{\mathrm{HOMO}}$, while decreasing the $E_{\mathrm{LUMO}}$ in the sequence of $1 i<2 i<3 i(i=\mathrm{a}, \mathrm{b}$, and $\mathrm{c})$. From these results, it may be concluded 
that comparatively to 1a, extending the side group with an aromatic ring destabilizes the HOMO, which becomes more stabilized by the $\mathrm{O} / \mathrm{NH}$ substitution. A comparison of $2 \mathrm{i}$ to $3 \mathrm{i}$ (or $4 \mathrm{a}$ ) shows that the HOMO is even more destabilized by a lateral extension. E-D capacity is then increased within the same order as confirmed by IP calculations whose results are summarized in Table 1 . The results show a tight dependence of the E-D capacity of the TPP-like molecules on that of the free side group, resulting in some interesting implications for some aspects of OZ use: (i) The stability of the inclusion compound, $\operatorname{TPP}\left(\mathrm{I}_{2}\right)_{\mathrm{x}}$, and the operating temperatures may be improved by using $1 \mathrm{c}, 2 \mathrm{a}$, and $3 \mathrm{a}$ whose clathrates with many other molecules are already known, with the OZ- $\mathrm{I}_{2}$ inclusion compound based on 2 a being expected to be less stable than that based on 3a. (ii) The E-D capacity of TPP side groups appears to be tunable, allowing predictions to be made about the stability of the inclusion compounds of $\mathrm{OZ}$ and molecules of Lewis acidity comparable to that of $\mathrm{I}_{2}$.

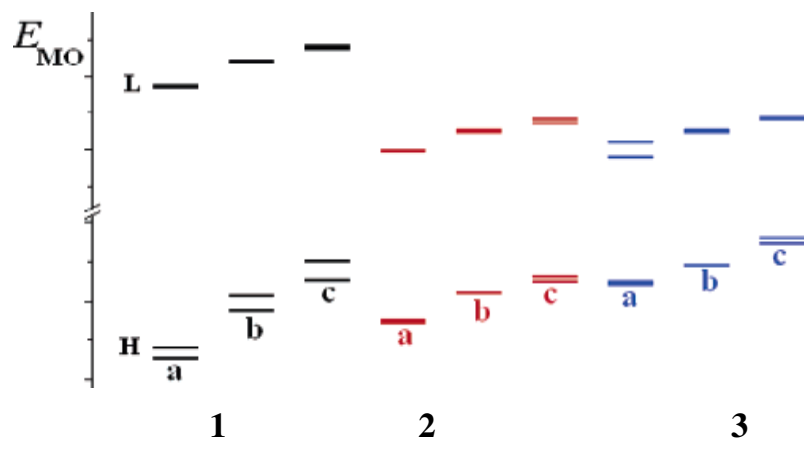

Fig. 4. PBE0 frontier molecular orbital (FMO) energy diagram for 1a-c, 2a-c, and 3a-c ( $\mathrm{L}=$ LUMOs, $\mathrm{H}=$ HOMOs)

\subsection{The $\mathrm{CH} / \mathrm{N}$ Heterosubstitution Effect on the Side Fragment}

With the aim to evaluate the influence of the $\mathrm{CH} / \mathrm{N}$ hetero-substitution on the molecular structure of TPP and TPP-like molecules, compounds 1a, $2 \mathrm{a}$ and their $\mathrm{CH} / \mathrm{N}$ substituted derivatives (1ad-e, 2ad-e) were considered for this issue. From the length of the side fragment viewpoint, on which depends the available space for adsorbates, we anticipate a decreasing diameter of the tunnel with the degree of $\mathrm{CH} / \mathrm{N}$ substitution within both TPP and TNP.

This can be explained by comparing the $\mathrm{C}-\mathrm{C}$ bond length of the unsubstituted bond (1.37-1.41 $\AA$ ) to that of the corresponding $\mathrm{C}-\mathrm{N}$ one $(1.28-1.30 \AA)$ in the $\mathrm{CH} / \mathrm{N}$ substituted derivatives. On the basis of our results the magnitude of the variation is expected in the decreasing order unsubsituted $>$ disustituted derivatives. Thus, the size of the adsorbing space in $\mathrm{CH} / \mathrm{N}$ derivatives of TPP may be anticipated to be smaller than that of TPP itself, while $\mathrm{CH} / \mathrm{N}$ derivatives of TNP would lead to crystals having a tunnel spacein between those with TPP and TNP. 
Table 1. The obtained electronic properties: the $\mathrm{IP}_{\mathrm{KT}}$, FMO energies, and $\mathrm{Eg}$ between $\mathrm{HOMO}$ and LUMO (eV)

\begin{tabular}{ccccc}
\hline compounds & $\mathrm{IP}_{\mathrm{KT}}$ & $\mathrm{E}_{\mathrm{HOMO}}$ & $\mathrm{E}_{\mathrm{LUMO}}$ & $\mathrm{Eg}$ \\
\hline $\mathbf{1 a}$ & 8.79 & -6.60 & -0.15 & 6.45 \\
$\mathbf{1 b}$ & 8.02 & -5.93 & 0.18 & 6.11 \\
$\mathbf{1 c}$ & 7.53 & -5.49 & 0.37 & 5.86 \\
$\mathbf{2 a}$ & 8.00 & -6.25 & -1.04 & 5.21 \\
$\mathbf{2 b}$ & 7.66 & -5.90 & -0.78 & 4.12 \\
$\mathbf{2 c}$ & 7.46 & -5.69 & -0.64 & 5.05 \\
$\mathbf{3 a}$ & 7.68 & -5.76 & -1.12 & 4.64 \\
$\mathbf{3 b}$ & 7.26 & -5.55 & -0.78 & 4.77 \\
$\mathbf{3 c}$ & 6.91 & -5.20 & -0.58 & 4.62 \\
$\mathbf{4}$ & 7.92 & -6.69 & 0.01 & 6.69 \\
$\mathbf{1 a d}$ & 10.94 & -8.77 & -0.35 & 8.42 \\
$\mathbf{1 a e}$ & 9.80 & -8.40 & -0.48 & 7.92 \\
$\mathbf{2 a d}$ & 9.11 & -7.91 & -0.90 & 7.01 \\
$\mathbf{2 a e}$ & 9.21 & -7.98 & -0.86 & 7.12 \\
$\mathbf{5 a f h}$ & 7.02 & -4.91 & -1.03 & 3.88 \\
$\mathbf{5 a f i}$ & 7.13 & -5.11 & -1.01 & 4.10 \\
$\mathbf{5 a g i}$ & 7.16 & -5.19 & -1.38 & 3.80 \\
$\mathbf{5 b f h}$ & 6.85 & -4.77 & -0.90 & 3.87 \\
$\mathbf{5 b f i}$ & 6.93 & -4.96 & -0.89 & 4.08 \\
$\mathbf{5 b g i}$ & 6.99 & -5.05 & -1.26 & 3.79 \\
$\mathbf{5 c f h}$ & 6.72 & -4.76 & -0.83 & 3.86 \\
$\mathbf{5 c f i}$ & 6.82 & -4.87 & -0.81 & 4.06 \\
$\mathbf{5 c g i}$ & 6.85 & -4.94 & -1.20 & 3.75 \\
$\mathbf{5 a f h}$ & 7.02 & -4.91 & -1.03 & 3.88 \\
$\mathbf{5 a f i}$ & 7.13 & -5.11 & -1.01 & 4.10 \\
$\mathbf{6 a f j}$ & 7.18 & -5.08 & -1.14 & 3.94 \\
$\mathbf{6 a f k}$ & 7.04 & -4.92 & -1.02 & 3.90 \\
$\mathbf{6 a g j}$ & 7.13 & -5.13 & -1.50 & 3.63 \\
$\mathbf{6 a g k}$ & 7.00 & -4.98 & -1.40 & 4.00 \\
$\mathbf{6 b f j}$ & 7.02 & -4.95 & -0.95 & 3.95 \\
$\mathbf{6 b f k}$ & 6.89 & -4.79 & -0.84 & 3.66 \\
$\mathbf{6 b g j}$ & 6.98 & -4.99 & -1.33 & 3.63 \\
$\mathbf{6 b g k}$ & 6.87 & -4.86 & -1.23 & 3.80 \\
$\mathbf{6 c f j}$ & 6.81 & -4.74 & -0.92 & 3.48 \\
$\mathbf{6 c f k}$ & 6.69 & -4.61 & -0.81 & -1.29 \\
$\mathbf{6 c g j}$ & 6.80 & -4.81 & -1.20 & \\
$\mathbf{6 c g k}$ & 6.69 & -4.68 & & \\
\hline & & & & \\
\hline
\end{tabular}

The $\mathrm{CH} / \mathrm{N}$ substitution in the side fragment decreases (and stabilizes) the HOMO and LUMO eigenvalues at the same time owing to the presence of two nitrogen atoms and very dependently on the position of the substituted $\mathrm{CH}$ group in the side fragment. Due to the inductive effect of the nitrogen atom, the HOMO gets stabilized in the sequence $1 \mathrm{a}<1 \mathrm{ae}<1 \mathrm{ad}$ within the subgroup of TPP and its $\mathrm{CH} / \mathrm{N}$ derivatives and in the sequence of $2 \mathrm{a}<2 \mathrm{ad}<2 \mathrm{ae}$ in the subclass of TNP and its $\mathrm{CH} / \mathrm{N}$ derivatives. The predicted net effect was that, in comparison to TPP, extending the side group with an aromatic ring (TNP) destabilizes the HOMO, which becomes more stabilized by $\mathrm{CH} / \mathrm{N}$ substitution. 


\subsection{The Effects of TTF-Like Fragments in the Side Groups}

To design novel materials combining a good E-D strength and "paddle wheel" molecular shape responsible for inclusion adducts formation, we introduce TTF-like fragments in to TPP by fused with phenyl ring (5) or substituting it (6), which may lead to potential candidates for superconductors, that may combine a good electrondonor ability and a possible inclusion adduct formation. The bridging parts by $\mathrm{O} / \mathrm{NH}$ substitution are also considered.

In general, most of the new derivatives are predicted to preserve the "paddle wheel" molecular shape, the TTF-containing side group retaining the TTF-like donor behavior (TTF-like moiety distortion into the planar) during the oxidization process. From the electron-donor ability point of view, the current study shows clearly that, comparatively to the commonly used electron donors, such as TTF, Tetramethyltetraselenafulvalene (TMTSF), Bis(ethylenedithio)tetrathiafulvalene (ET), Bis(ethylenedioxy)tetrathiafulvalene (BETS-TTF), and Bisethylenedioxytetrathiafulvalene) (BO), whose predicted $\mathrm{IP}_{\mathrm{KT}}$ ranges from 6.65-7.05 eV, a comparable E-D ability can be reached by adopting the building approach developed in this work (whose predicted $\mathrm{IP}_{\mathrm{KT}}$ ranges from 6.69-7.18 eV). An additional insight provided by the current results is that the $\mathrm{O} / \mathrm{NH}$ substitution induces a relatively significant decrease in the IP, increasing therefore the E-D strength. Finally, one may find from the same results that partial substitution leads to TTF-containing TPP analogs whose IP values (E-D strength) may be in between those of the corresponding derivatives from the total $\mathrm{O} / \mathrm{NH}$.

\section{Conclusion}

Using TPP as template, series derivatives or analogs were designed by chemical modification of TPP by the substitution of bridge part or side fragments. On the basis of DFT-BPE0/6-31G** quantum calculation, the results show a tight dependence of the E-D of the entire molecule on that of the side groups and bridge part, which may result in some interesting implications for some aspects of OZ use, i.e., (i) The stability of the inclusion compound, $\mathrm{OZ}-\mathrm{I}_{2}$, and the operating temperatures may be improved by using high E-D material (ii) The E-D capacity of TPP side groups appears to be tunable, allowing predictions to be made about the stability of the inclusion compounds of $\mathrm{OZ}$ and molecules of Lewis acidity comparable to that of $\mathrm{I}_{2}$. It was concluded that the total $\mathrm{O} / \mathrm{NH}$ substitution for the bridge part may significantly enhance the electron-donor capacity without altering the tolerance of TPP-like host materials to the guest molecules. The E-D capacity was found to be more significantly enhanced by a lateral than a linear extension with phenyl ring, while it decreased upon $\mathrm{CH} / \mathrm{N}$ heterosubstitution, which can affect the stability of some related host.....guest complexes in the same order. The extension (or substitution) of the phenylenedioxyl group with an aromatic ring especially by introducing TTF fragments significantly enhance the E-D. In addition, in comparison with the commonly used organic superconductors, most of the designed molecules with TTF fragments were predicted to show comparable or better E-D strength, suggesting them to be good candidates for organic superconductors. 
Acknowledgments. Financial supports from the NSFC (Nos. 50873032, 20773022), the NCET-06-0321, the JLSDP (20082212), and the NENU-STB-07-007 are gratefully acknowledged.

\section{References}

1. Chae, H.K., Siberio-Perez, D.Y., Kim, J.Y., Eddaoudi, G.M., Matzger, A.J., Keeffe, M.O., Yaghi, O.M.: A Route To High Surface Area, Porosity and Inclusion of Large Molecules In Crystals. Nature 427, 523-527 (2004); Ward, M.D.: Enhanced: Molecular Fuel Tanks. Science 300, 1104-1105 (2003); Kuznicki, S.M., Bell, V.A., Nair, S., Hillhouse, H.W., Jacubinas, R.M., Braunbarth, C.M., Toby, B. H., Tsapatsis, M.: A Titanosilicate Molecular Sieve with Adjustable Pores for Size-Selective Adsorption of Molecules. Nature 412, 720 $724(2001)$

2. Blau, W.J., Fleming, A.J.: Designer Nanotubes by Molecular Self-Assembly. Science 304, 1457-1458 (2004)

3. Whitesides, G., Grzybowski, M.B.: Self-Assembly at All Scales. Science 295, 2418-2421 (2002)

4. Allcock, H.R., Siegel, L.A.: Phosphonitrilic Compounds. III. Molecular Inclusion Compounds of Tris(o-phenylenedioxy)phosphonitrile Trimer. J. Am. Chem. Soc. 86, 5140 5144 (1964)

5. Allcock, H.R., Levin, M.L., Whittle, R.R.: Tris(o-phenylenedioxy)cyclotriphosphazene: The Clathration-Induced Monoclinic to Hexagonal Solid State Transition. Inorg. Chem. 25, 41-47 (1986)

6. Sozzani, P., Comotti, A., Simonutti, R., Meersmann, T., Logan, J.W., Pines, A.: A Porous Crystalline Molecular Solid Explored by Hyperpolarized Xenon. Angew. Chem. Int. Ed. 39, 2695-2699 (2000); Sozzani, P., Bracco, S., Comotti, A., Ferretti, L., Simonutti, R.: Methane and Carbon Dioxide Storage in a Porous van der Waals Crystal. Angew. Chem. Int. Ed. 44, 1816-1820 (2005); Sozzani, P., Comotti, A., Bracco, S., Simonutti, R.: A Family of Supramolecular Frameworks of Polyconjugated Molecules Hosted in Aromatic Nanochannels. Angew. Chem., Int. Ed. 43, 2792-2797 (2004)

7. Hertzsch, T., Budde, F., Weber, E., Hulliger, J.: Supramolecular-Wire Confinement of $\mathrm{I}_{2}$ Molecules in Channels of the Organic Zeolite Tris(o-phenylenedioxy)cyclotriphosphazene. Angew. Chem. Int. Ed. 41, 2281-2284 (2002)

8. Hertzsch, T., Kluge, S., Weber, E., Budde, F., Hulliger, J.: Surface Recognition of Dipolar Molecules Entering Channels of the Organic Zeolite Tris(o-phenylenedioxy)cyclotriphosphazene. Adv. Mater. 13, 1864-1867 (2001)

9. Allcock, H.R., Stein, M.T., Stanko, J.A.: The Crystal and Molecular Structure of Tris(2,2'dioxybiphenyl)cyclotriphosphazene. J. Am. Chem. Soc. 93, 3173-3178 (1971)

10. Allcock, H.R., Stein, M.T.: Clathration by Tris (2,3-naphthalenedioxy)cyclotriphosphazene. An X-ray Crystal and Molecular Structure Study. J. Am. Chem. Soc. 96, 49-52 (1974)

11. Allcock, H.R., Kugel, R.L.: Cyclized Products From the Reactions of Hexachlorocyclotriphosphazene (Phosphonitrilic Chloride Trimer) with Aromatic Dihydroxy, Dithiol, and Diamino Compounds. Inorg. Chem. 5, 1016-1020 (1966)

12. Siegel, L.A., Van den Hende, J.H.: The Crystal Structure of Molecular Inclusion Compounds of tris(o-phenylenedioxy)phosphonitrile Trimer. J. Chem. Soc. A., 817-820 (1967); Allcock, H.R., Allen, R.W., Bissel, E.C., Smeltz, L.A., Teeter, M.: Molecular Motion and Molecular Separations in Cyclophosphazene Clathrates. J. Am. Chem. Soc. 98, 5120-5125 (1976) 
13. Couderc, G., Hertzsch, T., Behrnd, N.-R., Kramer, K., Hulliger, J.: Reversible Sorption of Nitrogen and Xenon Gas by the Guest-free Zeolite Tris(o-phenylenedioxy)cyclotriphosphazene (TPP). Microporous and Mesoporous Materials 88, 170-175 (2006)

14. Hertzsch, T., Gervais, C., Hulliger, J., Jaeckel, B., Guentay, S., Bruchertseifer, H., Neels, A.: Open-Pore Organic Material for Retaining Radioactive $\mathrm{I}_{2}$ and $\mathrm{CH}_{3} \mathrm{I}$. Adv. Funct. Mater. 16, 268-272 (2006)

15. Breza, M.: On bonding in Cyclic Triphosphazenes. J. Mol. Struct (Theochem.) 505, 169177 (2000); Breza, M.: The Electronic Structure of Planar Phosphazene Rings Polyhedron 19, 389-397 (2000); Luana, L., Pendas, A.M., Costales, A.: Topological Analysis of Chemical Bonding in Cyclophosphazenes. J. Phys. Chem. A. 105, 5280 (2001); Waltman, R.J., Lengsfield, B., Pacansky, J.: Lubricants for Rigid Magnetic Media Based upon Cyclotriphosphazenes : Interactions with Lewis Acid Sites. Chem. Mater. 9, 2185-2196 (1997); Gahungu, G., Zhang, B., Zhang, J.: Theoretical Study of Tris(o-phenylenedioxy) cyclotrisphosphazene (TPP) Electronic Structure with Ab Initio and DFT methods. Chem. Phys. Lett. 388, 422-426 (2004); Gervais, C., Hertzsch, T., Hulliger, J.: Insertion of Dipolar Molecules in Channels of a Centrosymmetric Organic Zeolite: Molecular Modeling and Experimental Investigations on Diffusion and Polarity Formation. J. Phys. Chem. B. 109, 7961-7968 (2005)

16. Gahungu, G., Zhang, B., Zhang, J.P.: Influence of the Substituted Side Group on the Molecular Structure and Electronic Properties of TPP and Related Implications on Organic Zeolites Use. J. Phys. Chem. B 111, 5031-5033 (2007); Gahungu, G., Zhang, B., Zhang, J.P.: Design of Tetrathiafulvalene-Based Phosphazenes Combining a Good ElectronDonor Capacity and Possible Inclusion Adduct Formation (Part II). J. Phys. Chem. C 111, 4838-4846 (2007) ; Gahungu, G., Zhang, J. P.: Design of TTF-Based Phosphazenes Combining a Good Electron-Donor Capacity and Possible Inclusion Adduct Formation. J. Phys. Chem. B 110, 16852-16859 (2006)

17. Frisch, M.J., Trucks, G.W., Schlegel, H.B., Scuseria, G.E., Robb, M.A., Cheeseman, J.R., Montgomery Jr., J.A., Vreven, T., Kudin, K.N., Burant, J.C., Millam, J.M., Iyengar, S.S. Tomasi, J., Barone, V., Mennucci, B., Cossi, M., Scalmani, G., Rega, N., Petersson, G.A., Nakatsuji, H., Hada, M., Ehara, M., Toyota, K., Fukuda, R., Hasegawa, J., Ishida, M., Nakajima, T., Honda, Y., Kitao, O., Nakai, H., Klene, M., Li, X., Knox, J.E., Hratchian, H.P., Cross, J.B., Bakken, V., Adamo, C., Jaramillo, J., Gomperts, R., Stratmann, R.E., Yazyev, O., Austin, A.J., Cammi, R., Pomelli, C., Ochterski, J.W., Ayala, P.Y., Morokuma, K., Voth, G.A., Salvador, P., Dannenberg, J.J., Zakrzewski, V.G., Dapprich, S., Daniels, A.D., Strain, M.C., Farkas, O., Malick, D.K., Rabuck, A.D., Raghavachari, K., Foresman, J.B., Ortiz, J.V., Cui, Q., Baboul, A.G., Clifford, S., Cioslowski, J., Stefanov, B.B., Liu, G., Liashenko, A., Piskorz, P., Komaromi, I., Martin, R.L., Fox, D.J., Keith, T., Al-Laham, M.A., Peng, C.Y., Nanayakkara, A., Challacombe, M., Gill, P.M.W., Johnson, B., Chen, W., Wong, M.W., Gonzalez, C., Pople, J.A.: Gaussian 2003, Revision B.05. Gaussian, Inc., Pittsburgh (2003)

18. Adamo, C., Barone, V.: Toward Reliable Density Functional Methods without Adjustable Parameters: The PBE0 Model. J. Chem. Phys. 110, 6158-6170 (1999); Van Voorhis, T. Scuseria, G. E.: A Novel Form for the Exchange-correlation Energy Functional. J. Chem. Phys. 109, 400-410 (1998)

19. Hariharan, P.C., Pople, J.A.: Accuracy of $\mathrm{AH}_{\mathrm{n}}$ Equilibrium Geometries by Single Determinant Molecular Orbital Theory. Mol. Phys. 27, 209-214 (1974); Gordon, M.S.: The Isomers of Silacyclopropane. Chem. Phys. Lett. 76, 163-168 (1980); Frisch, M. J., Pople, J.A., Binkley, J.S.: Self-consistent Molecular Orbital Methods 25. Supplementary Functions for Gaussian Basis Sets. J. Chem. Phys. 80, 3265-3269 (1984)

20. Koopmans, T.: Über die Zuordnung von Wellenfunktionen und Eigenwerten zu den Einzelnen Elektronen Eines Atoms. Physica 1, 104-113 (1934) 